\title{
Institutions versus Geography: \\ Subnational Evidence from the United States
}

Eric V. Clifton and Alma Romero-Barrutieta 



\title{
IMF Working Paper
}

IMF Institute

Institutions versus Geography: Subnational Evidence from the United States

\author{
Prepared by Eric V. Clifton and Alma Romero-Barrutieta ${ }^{1}$
}

July 2006

\begin{abstract}
This Working Paper should not be reported as representing the views of the IMF. The views expressed in this Working Paper are those of the author(s) and do not necessarily represent those of the IMF or IMF policy. Working Papers describe research in progress by the author(s) and are published to elicit comments and to further debate.

Empirical studies of the impact of geography and institutions on growth and development at the international level have become common place, but the high degree of abstraction at that level has led to calls for subnational studies. This paper examines these issues for a region of the United States, Appalachia, where the specific factors at play are identified and measured thus obviating the need for instrumental variable techniques. The evidence suggests that initial conditions, including both geography and institutions, are very important for economic development, having significant effects lasting hundreds of years.
\end{abstract}

JEL Classification Numbers: O11, O18, R11

Keywords: Economic growth; poverty; institutions; geography; Appalachia

Author(s) E-Mail Address: eclifton@imf.org; rome0051@umn.edu

\footnotetext{
${ }^{1}$ We are grateful to J. Rappaport for providing the data for the topographical variable and for comments, to Mark Parrett for research assistance, and to A. Bulir, S. Johnson, J. LeSage, C. McNeilly, and Y. Kinoshita for helpful comments. Ms. Romero-Barrutieta is at the University of Minnesota. This paper was completed when she was an intern at the IMF.
} 


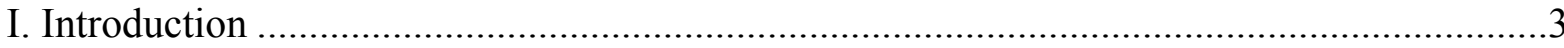

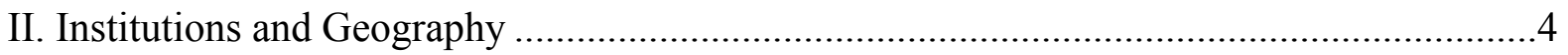

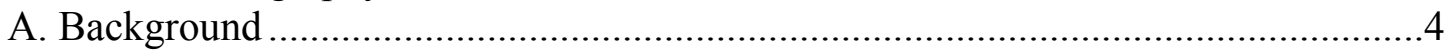

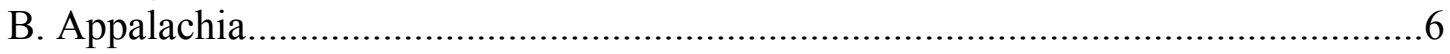

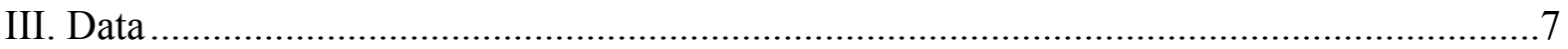

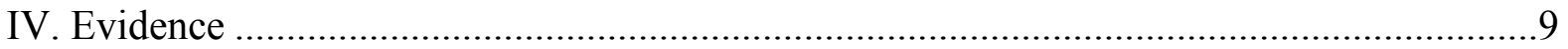

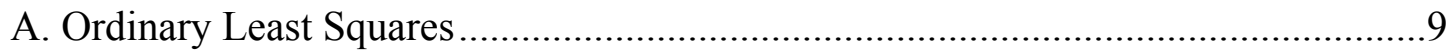

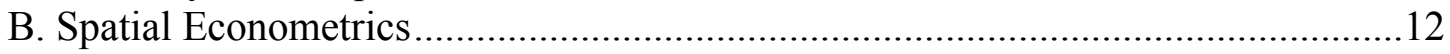

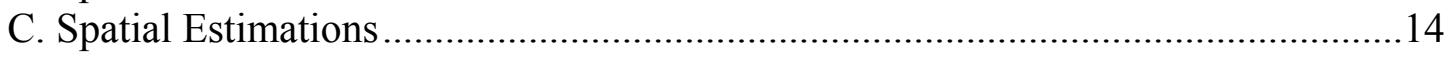

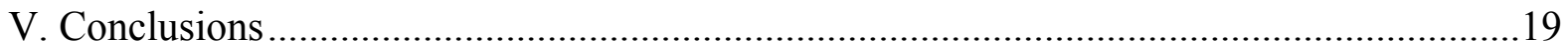

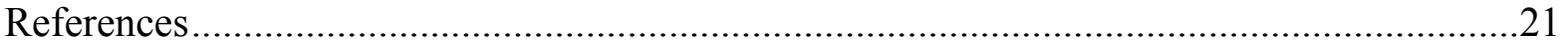

Tables

1. Ordinary Least Squares Estimates (Nonmetropolitan U.S. Counties).............................10

2. Ordinary Least Squares Estimates (Nonmetropolitan Central Appalachian Counties) ......10

3. Bayesian Geographically Weighted Regression Model .............................................15

Figures

1. The Repeopling of Southern Appalachia, 1740-1840 …............................................

2. Percent of Total Population in Poverty by Country: 2003 ...........................................11

3. BGWR and GWR Parameter Estimates........................................................................ 16

4. BGWR Negative Parameter Estimates With a Distance Decay Prior ...............................17

5. BGWR Negative Parameter Estimates With a Contiguity Prior ......................................18 


\section{INTRODUCTION}

The literature on economic growth and cross-country income differences is rife with discussions on the relative importance of institutions and geography but, as yet, no consensus exists. ${ }^{2}$ In addition, there is disagreement in the literature about the causal relationship between poverty (as measured by inequality) and growth. ${ }^{3}$ Empirical studies of explanatory factors for growth or income differences most frequently use cross-country data. One problem with this literature is that international differences among countries for important geographical or institutional features can be so wide that there are what Durlauf and others (2005) call "exchangeability violations," calling into question the robustness of the empirical results. These authors have also criticized the use of instrumental variables in much of this literature. Others, citing the limitations of existing cross-country empirical work, have expressed the need for subnational studies. ${ }^{5}$ This paper examines the impact of geography and institutions for a homogenous subnational region where the specific factors at play are identified and measured thus obviating the need for instrumental variable techniques. ${ }^{6}$ The region used is Appalachia in the United States, ${ }^{7}$ an area where nonmetropolitan poverty is widespread. Easterly (2001) refers to parts of Appalachia as being in a poverty trap and Duncan (1992) notes that Appalachia has some characteristics similar to a developing country.

The evidence presented here tentatively suggests that initial conditions are very important for economic development and can have significant effects lasting hundreds of years. The results indicate that, contrary to popular belief, geographical isolation may not be the critical factor behind widespread poverty in Appalachia. In contrast, the evidence suggests that institutional factors may play a dominant role in the region's lagging development.

The next section gives some background; the third section describes the data used; the fourth provides the evidence; and the final section draws some conclusions.

\footnotetext{
${ }^{2}$ For example, Acemoglu and others (2004), Easterly and Levine (2003), Glaeser and others (2004), Olsson and Hibbs (2005) and Parente and Prescott (2004).

${ }^{3}$ Kanbur (2001).

${ }^{4}$ For example, omitted variables or parameter heterogeneity across observations.

${ }^{5}$ For example, Srinivasan (2001), Ravallion (2001), and Besley and Burgess (2003). Mitchener and Mclean (2003), for example, find that institutional and geographic characteristics influence differences in productivity levels across U.S. states. Banerjee and Iyer (2005) look at subnational explanations of economic performance in India.

${ }^{6}$ Engerman and Sokoloff (2002) is an example of a search for specific institutions and factor endowments that played a role in the development of new world economies.

${ }^{7}$ Definitions of Appalachia have varied over time (Pollard (2003)). Central Appalachia as used here includes the Appalachian counties of Kentucky, Maryland, Virginia, West Virginia, northwest Tennessee, and northeast North Carolina. As Widner (1974) discusses, this is the area considered the most "typically" Appalachian and where poverty is most severe.
} 


\section{INSTITUTIONS AND GEOGRAPHY}

\section{A. Background}

The literature on economic growth is very broad, with theories extending from HarrodDomar to unified growth and with empirical work covering areas such as convergence, growth accounting and regressions on the determinants of growth. ${ }^{8}$ In the growth regressions literature, controversy rages about the relative roles of geography and institutions in explaining economic growth and relative international income levels. Geography and institutions are, of course, not mutually exclusive theories but are rather "open-ended."

Regarding whether it makes a difference to focus on relative growth rates (as in growth accounting) or relative income levels (as in development accounting), Caselli (2005) says that these concepts are based on the same idea but with cross-country differences replacing cross-time differences. One advantage of trying to explain relative income differentials, however, is that it is not necessary to have a series of growth rates going back to the time when regions started to diverge. Trying to look at relative growth rates often forces the researcher to focus only on part of the development experience, which may be misleading. ${ }^{9}$ In any case, economic growth rates are not available for U.S. counties back to 1800, but data are available for point-in-time comparisons. For these point-in-time comparisons, this study uses relative poverty rates rather than relative income levels. While these concepts are significantly negatively correlated, income differentials focus on differences among the means of county income distributions whereas poverty rates focus on the relative number of people at the lower end of the income distributions. ${ }^{10}$ The view here is that the latter gives a better picture of the relative development of the individual counties which is what the institutional factors studied are meant to explain.

Since empirical work looking at the role of geography has been typically done with international comparisons, a long list of variables has been used. For example, Rodrik and others (2002) mention land area in the tropics, access to the sea, number of frost days per month in winter, area covered by frost, oil exporting capacity, prevalence of malaria, mean temperature, and distance from the equator. The last is one of the most popular explanatory variables used based on the simple observation that advanced countries are in the temperate zones and the poor in the tropics and it is easy to measure.

Unfortunately, as noted in Diamond (1997) and Olsson and Hibbs (2003), a large number of geographic factors can interact in complex ways to influence development. On the global level, it is difficult to measure all of the factors and to know how to combine them. One

\footnotetext{
${ }^{8}$ Aghion and Durlauf (2005).

${ }^{9}$ See Galor (2005) concerning problems with not considering "the growth process in its entirety."

${ }^{10}$ Durlauf and others (2005) point out that there has been relatively little work on distribution issues in growth econometrics.
} 
factor may be important in one area, another somewhere else, leading the researcher to come to the conclusion that none of the geographic factors is significant. These authors' work implies that it is important to consider all of the biogeographic factors that could have had a significant impact on economic development at the very beginning of a society. Given the relatively small area covered in this paper, most biogeographical features are very similar. However, the degree of mountainousness (as defined below) differs from one county to another, often considerably. This narrow geographical feature, mountainousness, has been discussed widely (although anecdotally) for a long time as an explanation of poverty in Appalachia. Thus it may meet the requirement of being the essential geographic feature affecting relative development.

Mountainousness could affect economic development in many ways but in the economic literature, it perhaps can be most closely related to the notion of transport costs. The idea being that a more mountainous region would have higher transport costs and thus be less competitive than other regions and therefore less developed. The importance of transport costs in economic development is far from agreed in the literature, however. ${ }^{11}$ Some suggest that even if transport costs were important in the early stages of development, the effect should diminish over time. ${ }^{12}$ However, in that case, while the impact of transport costs might not show up in growth rates long after the initial period, the effect still should be apparent in relative income levels.

The work on the impact of institutions on economic growth has exploded in recent years with Acemoglu and others (2001) being a widely cited example. These empirical studies try to look at the effect of early institutions on economic growth. Since measurements for institutions far back in time are often not available, instrumental variable techniques have been used to connect available data with notions of past institutions that cannot be directly measured. However, these instrumental variable studies have been subject to methodological criticism, such as by Durlauf and others (2005). For example, in the growth econometrics literature an instrument must not be a direct explanation of growth. In most cases it is difficult to argue that the instrumental variable itself had no direct effect on growth.

Another criticism of the empirical literature on institutions is that the choice of variables sometimes seems more driven by data availability than by a relationship to a fundamental institutional concept. ${ }^{13}$ The institutional variables sometimes refer to something that is potentially short-lived rather than being long-lasting (e.g., survey scores on institutional quality). As well, the variables are sometimes not consistent with North's (1981) definition

\footnotetext{
${ }^{11}$ For example, reporting on the "floor discussion" in Gallup and others (1998), it is said that discussants "downplayed the importance of transport costs in economic development."

${ }^{12}$ Venebles (1998).

${ }^{13}$ Glaeser and others (2004).
} 
of institutions as putting a constraint on the behavior of individuals (e.g., dictators that follow good policies get good scores by many measures of institutional quality). ${ }^{14}$

\section{B. Appalachia}

Appalachia is a mountainous region of the United States in close proximity to the eastern seaboard. The region covers about 200,000 square miles and has some 23 million people with a total personal income of almost US $\$ 600$ billion. ${ }^{15}$ Compared internationally, its economy would be somewhere around the size of the Netherlands or Spain. Nonetheless, by U.S. standards, it is a region of considerable poverty. In central Appalachia (the focus of this paper), the poverty rate is some 27 percent, more than twice the national average. Appalachia is an interesting case study for looking at the effects of geography and institutions on poverty because its poverty cannot be easily explained by factors such as the problems of inner cities (it is significantly rural); racial discrimination (as in poor areas of Mississippi); recent immigration (as in parts of the Rio Grande Valley); or the legacy of wars against Native Americans (as in parts of the Dakotas). ${ }^{16}$ The usual explanations of poverty in Appalachia are, rather, isolation (i.e., geography) or domination by elites (i.e., institutions).

A long-standing explanation of the widespread poverty in Appalachia is based on geography, in particular mountainousness. For example, Santopietro (2002), p. 898 discusses the view of many that "the primary obstacle to growth was believed by many to be the isolation caused by the difficulty of access to and within the mountainous region." Tobacco, an important cash crop in parts of Appalachia, would have higher transport costs in more mountainous areas, for example. This geographic explanation has had an important impact on U.S. government policies to eradicate poverty in Appalachia which have heavily emphasized highway construction to reduce isolation. ${ }^{17}$

Dunaway (1996) discusses the institutional structure that developed during Appalachia's settlement by Europeans as a cause of poverty. Central Appalachia was significantly depopulated during 1600-1750 of its native population. Due to warfare and disease, the native population fell by some 90 percent through the 1700s. Hunting and related export activities during this period also led to the decimation of wildlife and substantial deforestation. In the late 1700s, the repopulation of the area by Euro-Americans began and picked up speed after the Revolutionary War. The expansion of new population into the region was mostly over by 1840 (Figure 1). Land policies of the colonial authorities favored

\footnotetext{
${ }^{14}$ See Easterly and Levine (2003) for some choices of variables that only loosely fit North's definition of institutions.

${ }^{15}$ See the website of the Appalachian Regional Commission, www.arc.gov.

${ }^{16}$ Pollard (2003) makes the point that Appalachia has little racial or ethnic diversity and the residents are more likely to be natives of their home states than other Americans.

${ }^{17}$ Wood and Bishak (2000). In 1964, the U.S. President reported to Congress that economic growth in Appalachia would not be possible until the region's isolation had been overcome.
} 
large land speculators. By the early 1800's much of the area had been carved up into large estates. With small exceptions, lands were privatized before public domain and federal land policy was formulated. Land was heavily concentrated in the hands of local elites and absentee property owners. By 1800, three-quarters of the region's acreage was absenteeowned. Landed property owners strengthened their dominant position over land and the means of production far beyond what was true in other regions of the United States. The elites also guided the development of the economies and public infrastructure to support improvements that would bolster their export activities.

This institutional development, in North's sense of putting constraints on the behavior of individuals, was very different from what occurred in the midwest and western United States and previously in the original colonies which were more heavily urbanized and with more emphasis on manufacturing and with greater opportunities for the generation of employment. Dunaway's hypothesis is that the very early institutional structure of the region set it on a course that was detrimental to the long-term development of its economy.

Of course, other institutional developments over the centuries in Appalachia have also been problematic. ${ }^{18}$ In any case, there are many types of institutions, and measures thereof, and any one metric can only cover part of the picture. However, a measure that gets at the essence of the institutional problem would presumably be highly correlated with other measures of institutional problems. In this paper, the measure of institutions is the percent of farmland under local control (details below).

\section{DATA}

In this paper a subset of Appalachian counties covered by the Appalachian Regional Commission (ARC) is used to ensure that the geographical and institutional initial conditions are very similar across all observations. Nonmetropolitan Appalachian counties of Kentucky, Maryland, North Carolina, Tennessee, Virginia and West Virginia, above the $36^{\text {th }}$ parallel, are used as these counties were largely resettled through lands granted in large tracts by colonial authorities or by post-revolutionary grants or sales and had much the same history from the time of resettlement to 1780 (Figure 1). ${ }^{19}$ Urbanized counties are excluded as the issues with urban poverty and rural poverty are very different. ${ }^{20}$ The selected area has a relatively uniform geography and climate (except that some counties are more mountainous than others). This subset of Appalachian countries allows this study to focus only on variation in mountainousness and the measure of institutions used.

\footnotetext{
${ }^{18}$ Lee (1974) discusses how corrupt politics in some parts of Appalachia contributed to poverty.

${ }^{19}$ Dunaway (1996).

${ }^{20}$ Khan (2000).
} 
Figure 1: The Repeopling of Southern Appalachia, 1740-1840

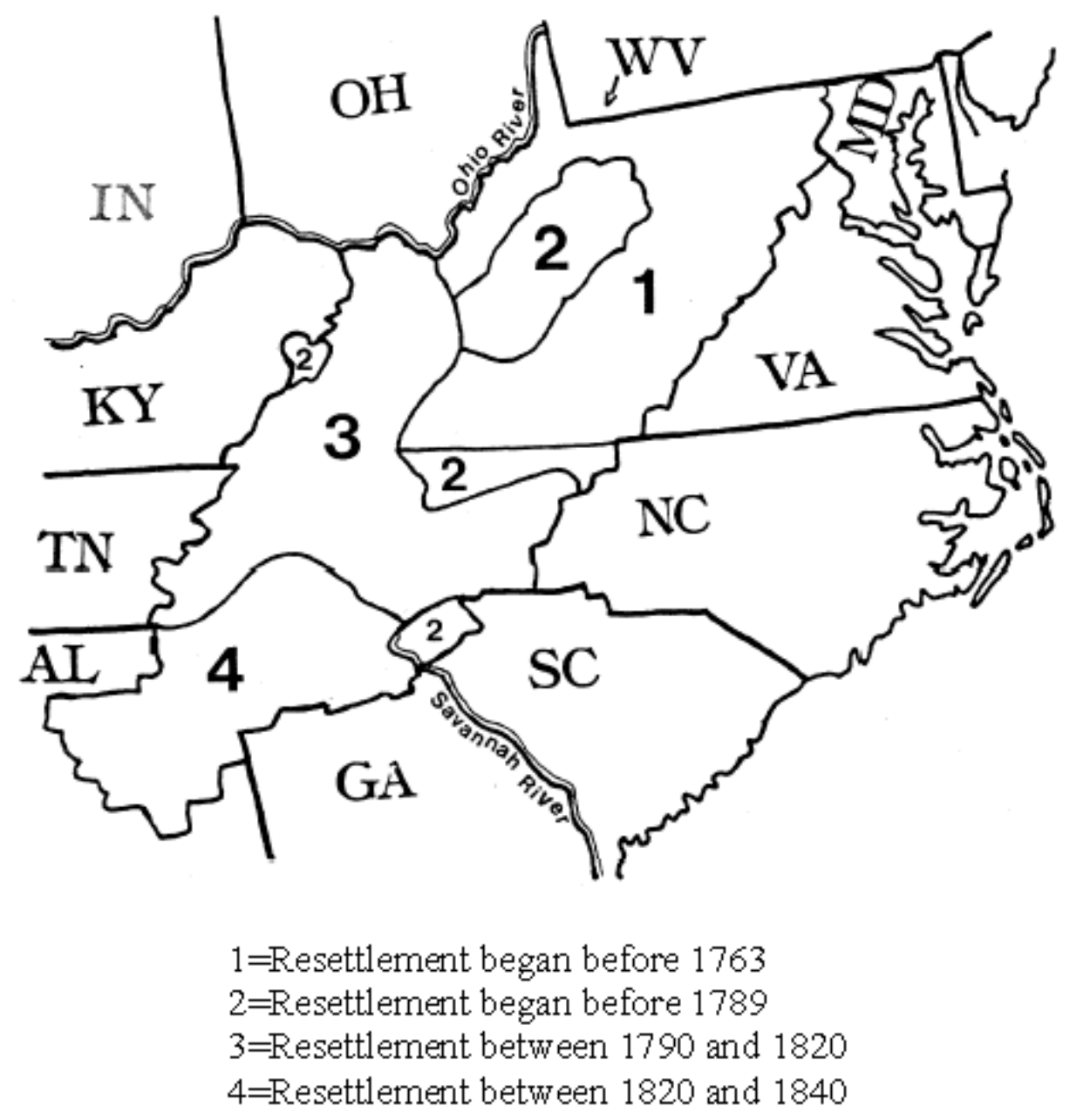

Source: From The First American Frontier: Transition to Capitalism in Southern Appalachia, 1700-1860 by Wilma A. Dunaway. Copyright (c) 1996 by The University of North Carolina Press. Used by permission of the publisher. www.uncpress.unc.edu 
The measure of mountainousness is from data used in Rappaport and Sachs (2003). The variable is derived from the standard deviation of altitude within a county divided by total county land area. If this variable is positively related to poverty it would imply that more mountainous counties are poorer. The data on poverty rates (percent of people of all ages) are from Small Area Income and Poverty Estimates (1989) by the U.S. Census Bureau.

A crucial institutional factor influencing the development of Appalachian counties was the degree to which land resources were controlled by local residents or absentee landlords. The earliest consistent information available on land-holdings on a county-level basis is from the 1910 U.S. Census. While some changes in landholding patterns between resettlement and 1910 likely occurred, there is no evidence to suggest that using this variable as an indicator of relative landholding patterns some hundred years earlier would be substantially biased. ${ }^{21}$ The institutional variable is defined as the number of acres of land in farm operation by owners divided by the total number of acres of land in farms (improved and unimproved). The higher this percentage, the relatively more of the local economy is operated by local residents. The hypothesis is that this variable is negatively related to poverty. Regarding North's definition of institutions, this variable measures what ex-post has turned out to be a long-lasting characteristic. Since landownership patterns were often set in place by colonial authorities in coastal cities before the actual Euro-American settlers arrived in Appalachia, the direction of any causality is clear. Landowning patterns put constraints on the economic choices available to residents.

\section{EVIDENCE}

In this section we present OLS estimates as the benchmark model to test our hypothesis, then exploit recent developments in the spatial econometric literature to improve the efficiency of the estimates and robustness of the results. In particular, this paper employs the Bayesian approach to geographically weighted regression methods (BGWR) introduced by LeSage (1999) to overcome heteroskedasticity problems and incorporate geographic characteristics of the sample data in the analysis.

\section{A. Ordinary Least Squares}

We apply a traditional OLS regression method to a sample of 1,887 nonmetropolitan U.S. counties, and secondly to a sample of 115 central Appalachian counties to assemble evidence of the relationship among poverty rates, geography and institutions (Tables 1 and 2). In both cases, parameter estimates indicate a negative relationship between poverty rates and each explanatory variable, suggesting that mountainous nonmetropolitan counties with land resources largely controlled by local residents have a relatively lower poverty rate.

${ }^{21}$ Dunaway (1996) notes that early landowning patterns in Appalachia were in many cases maintained well into the $20^{\text {th }}$ century. 
Table 1: Ordinary Least Squares Estimates

\begin{tabular}{lcccccc}
\hline $\begin{array}{l}\text { Nonmetropolitan U.S. Counties } \\
\text { Dependent variable } \\
\text { Number of observations }\end{array}$ & $\begin{array}{c}\text { Poverty rate } \\
\text { R-squared }\end{array}$ & 1887 & & & & \\
Adjusted R-squared & & 0.283 & & & & \\
& & 0.073 & & & & \\
& & & & & \\
Geography & Coefficient & Standard Error & $\mathbf{t}$ Statistic & $\mathbf{P}>\mathbf{t}$ & [95\% Confidence Interval] \\
Institutions & -12.858 & 4.319 & -2.98 & 0.003 & -21.328 & -4.387 \\
Constant & -7.02 & 1.13 & -6.20 & 0.000 & -9.24 & -4.80 \\
\hline
\end{tabular}

A total of 123 counties were deleted from the sample mainly due to lack of land-ownership data. A negative sign on the coefficients means that an increase in mountainousness or local land control is associated with a decline in poverty.

Table 2: Ordinary Least Squares Estimates

\begin{tabular}{|c|c|c|c|c|c|c|}
\hline \multicolumn{7}{|c|}{ Nonmetropolitan Central Appalachian Counties } \\
\hline \multicolumn{2}{|c|}{ Dependent variable } & Poverty rate & & & & \\
\hline \multicolumn{2}{|c|}{ Number of observations } & 115 & & & & \\
\hline \multicolumn{2}{|c|}{ R-squared } & 0.102 & & & & \\
\hline \multirow[t]{2}{*}{ Adjusted R-squared } & & 0.086 & & & & \\
\hline & Coefficient & Standard Error & t Statistic & $P>t$ & \multicolumn{2}{|c|}{ [95\% Confidence Interval] } \\
\hline Geography & -52.488 & 17.459 & -3.01 & 0.003 & -87.081 & -17.896 \\
\hline Institutions & -16.027 & 7.994 & -2.00 & 0.047 & -31.865 & -0.188 \\
\hline Constant & 40.853 & 6.720 & 6.08 & 0.000 & 27.537 & 54.168 \\
\hline
\end{tabular}

Conjectures solely based on these regressions could lead to erroneous or inadequate inferences, however, not only as a result of potential misspecification problems captured by the low R-squares, but also due to the counterintuitive assumption that the same relationship between poverty rates, geography and institutions prevails for all non-metropolitan U.S. counties regardless of their location. The pattern illustrated by the nationwide distribution of poverty rates in Figure 2 provides evidence against an invariant relationship.

A possible explanation for the low explanatory power of the OLS estimates is the method's lack of ability to capture locational aspects of the data, particularly the effect that each county may have on adjoining counties, for example, the relationship between poverty rates and institutions in a mountainous county surrounded by other mountainous counties might be different than if it is not. Consequently, low R-squares may also be indicative of the relevance that spatial linkages have at the county level and that the simple linear relationship embedded in the OLS fails to capture, suggesting that more powerful techniques like geographically weighted methods are required to draw meaningful inferences for central Appalachian counties. We conduct standard robustness tests to support this claim. 


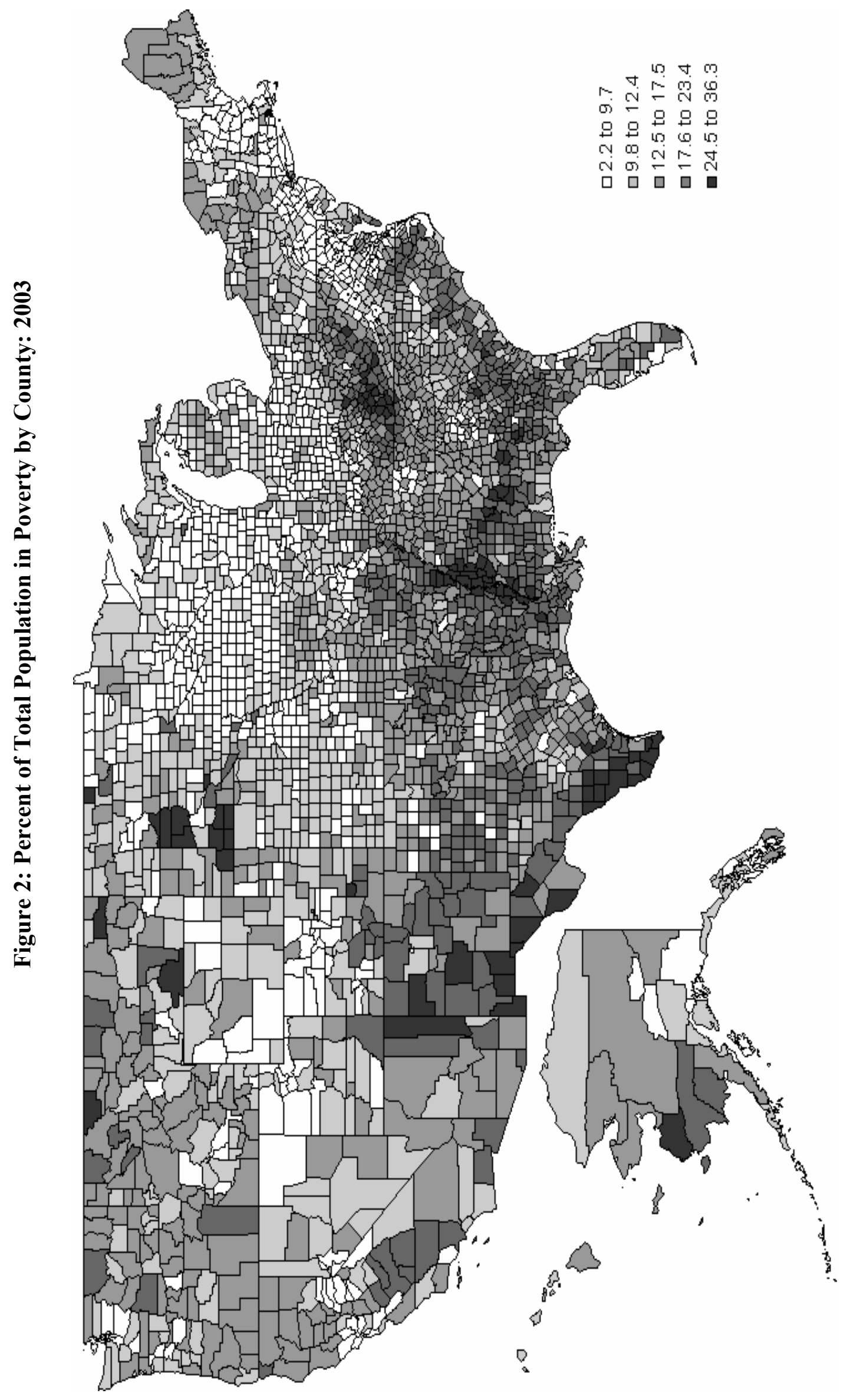


Since the center of our analysis is the effect that geography and early institutional arrangements have on poverty rates we will abstract from including additional explanatory variables. The implicit assumption is that most other variables that effect relative poverty rates (e.g., health and education) are functions of geography and institutions and thus we are looking at a reduced-form relationship. Also, while many variables (e.g., Solow variables) might effect relative growth rates or income levels, there does not seem to be an obvious reason why they would effect poverty differentials. There are some variables, however, such as the intelligence or the financial resources of the initial settlers, that could conceivably be considered here but no information is available on them.

Heteroskedasticity: We test the residuals for heteroskedasticity using a Cook-Weisberg test and reject the null hypothesis of constant variance at the $1 \%$ level of significance. A White's test confirms the presence of nonconstant variance in the sample. As will be argued below, the spatial econometric technique used in this paper addresses the problem of heteroskedasticity by exploiting the geographical dependence of the variance.

Outlier effects: We examine standardized and studentized residuals and did not find influential outliers in the sample, except for a single observation.

\section{B. Spatial Econometrics}

LeSage (1999) argues that when sample data has a locational component, two problems may arise: spatial dependence between observations and spatial heterogeneity. In terms of the classical regression model, spatial dependence violates the standard assumption of fixed explanatory variables in repeated sampling since observations with locational components depend on the rest of the observations in the sample data. Furthermore, assumptions of linearity and constant variance are violated when data vary across space, a concept known as spatial heterogeneity.

Spatial econometrics methods are designed to correct the effects of nonconstant variance as well as fluctuations in relationships among observations. Typically these methods rely on sample data to incorporate spatial effects such as decay of influence with distance, similarity of neighboring observations, and systematic changes in parameters with movement through space.

We apply the BGWR method to our sample of 115 central Appalachian counties to infer relationships over space between poverty rates, geography and institutions, incorporating prior information regarding the parameter smoothing relationship ${ }^{22}$ and nonconstant variance. LeSage (2004) describes the BGWR statistical model by:

$W_{i} y=W_{i} X \beta_{i}+W_{i} \varepsilon_{i}$

${ }^{22}$ The type of existing linkage between neighboring observations. 
$\beta_{i}=\left(w_{i 1} \otimes I_{k} \ldots . . w_{i n} \otimes I_{k}\right)\left(\begin{array}{c}\beta_{1} \\ \cdot \\ \cdot \\ \beta_{n}\end{array}\right)+u_{i}$

where $y$ denotes an $n x 1$ vector of dependent variable observations collected at $n$ points in space, $X$ an $n x k$ matrix of explanatory variables and $\varepsilon$ an $n x 1$ vector of normally distributed constant variance disturbances indexed by observation $i$. The terms $w_{i j}$ represent normalized distance-based weights such that the row vector $\left(w_{i 1} \ldots . . w_{i n}\right)$ sums to one and $w_{i i}=0$. In the paper we specifically use the geograpically weighted regression (GWR) distance weighting function $w_{i j}=\exp \left(-d_{i j} / \theta\right) / \sum_{j=1}^{n} \exp \left(-d_{i j} / \theta\right)$ to define the spatial weight matrix $W_{i}$ such that the relationship over space between observation $i$ and observation $j$ decays exponentially with distance $d_{i j}$ at rate $\theta$.

Equation (2) captures the parameter smoothing relationship among spatial observations by defining the parameter estimate $\beta_{i}$ corresponding to each observation $i$ as a convex combination of the parameter estimates from all other observations $\beta_{j}, j=1, \ldots . n$, weighted by $w_{i j}$. The term $u_{i}$ represents prior uncertainty about the smoothing relationship.

It is assumed that the error terms $\varepsilon_{i}$ and $u_{i}$ follow distributions:

$$
\begin{aligned}
& \varepsilon_{i} \sim N\left[0, \sigma^{2} V_{i}\right], V_{i}=\operatorname{diag}\left(v_{1}, v_{2} \ldots . ., v_{n}\right) \\
& u_{i} \sim N\left[0, \sigma^{2} \delta^{2}\left(X^{\prime} W_{i} X\right)^{-1}\right]
\end{aligned}
$$

The unknown variance parameters $\left(v_{1}, v_{2} \ldots . ., v_{n}\right)$ introduced by LeSage (1997) accommodate spatial heterogeneity by downweighting outliers and aberrant observations. He assumes that the prior distribution of the $v_{i}$ terms is an independent $\chi^{2}(r) / r$ distribution, which reduces the additional $n$ parameters to be estimated to a single hyperparameter $r$ since the $\chi^{2}$ distribution is a single parameter distribution. A small value of $r$ would indicate a prior belief of heterogeneity, in which case the $v_{i}$ terms would take large values and assign small weights to deviant observations.

As LaSage (1999) points out, the term $u_{i}$ represents prior uncertainty about the smoothing relationship over space and it is assumed to follow a normal distribution with mean zero and a variance based on Zellner's g-prior, a conventional prior in Bayesian variable selection. Equation (4) indicates that the variance of $u_{i}$ is proportional to the GWR variance- 
covariance matrix with the hyperparameter $\delta^{2}$ regulating the degree of adherence between parameter estimates and the proposed smoothing relationship. The smaller the difference between the resulting $\delta$ value and its prior, the tighter the smoothing restriction is imposed, resulting in individual parameter estimates $\beta_{i}$ computed as a distance-weighted linear combination of the estimates from adjoining observations.

\section{Spatial Estimations}

In order to infer relationships over space among poverty rates, topography and ownership ratios for the nonmetropolitan central Appalachian counties we estimate the following regression model:

povertyrate $_{i}=\beta_{0 i}+\beta_{1 i}$ geography $_{i}+\beta_{2 i}$ institutions $_{i}+\varepsilon_{i}$

Where povertyrate $_{i}$, geography $_{i}$ and institutions $_{i}$ are indexed by county $i=1, \ldots ., 115$. $^{2}$

Parameter specifications to our BGWR model include a) an exponential weighting function, b) a prior belief that the smoothing relationship among neighboring locations decays with distance, and c) parameter settings for the Bayesian prior so as to produce robust estimates: a hyperparameter $r=1$ to indicate a strict belief in heteroskedasticity, a diffuse $\delta$ value generated by data and scaled down by 0.1 as to impose a tight parameter smoothing relationship on the BGWR estimates.

We apply 5000 draws with the first 500 observations to be discarded by the Gibbs sampling process. ${ }^{23} \mathrm{We}$ also set our priors so as to get robust parameter estimates in order to avoid convergence problems. Nevertheless, a potential drawback from imposing a tight smoothing parameter specification is that estimates could be biased in case the sample data are inconsistent with the proposed parameter smoothing.

\footnotetext{
${ }^{23}$ As explained in LeSage (2004) this process draws a large random sample from a probability density instead of precisely computing it.
} 
Figure 3 graphs the coefficient estimates from the BGWR and GWR methods for comparison purposes and Table 3 shows the Bayesian output table. Using a diffuse $\delta=24.015$ prior we obtain a value of $\delta=25.27$, indicating consistency between the distance-based smoothing relationship prior and the data. We find that for 101 observations a negative relationship between poverty rates, geography and institutions is confirmed. Sixty-one of them have significant parameter estimates with $95 \%$ probability (most of them located in the states of Virginia and West Virginia), 4 have significant estimates for geography with $95 \%$ probability and for institutions with $90 \%$ probability. Two observations show the reverse outcome. Figure 4 maps the results.

Table 3: Bayesian Geographically Weighted Regression Model

\begin{tabular}{lclc}
\hline Nonmetropolitan Central Appalachian Counties & & \\
Dependent variable & Poverty rate & r value & 1 \\
Number of observations & 115 & delta value & 25.27 \\
Number of variables & 3 & Bandwidth & 1.00 \\
R-squared & 0.382 & Number of iterations & 13 \\
Number of draws & 5000 & Decay type & Exponential \\
Discarded observations & 500 & Prior type & Distance \\
\hline
\end{tabular}

Ideally a robust result to support our hypothesis would be one with all negative and statistically significant estimates for both variables, nevertheless, due to the trade-off between efficiency and bias when using Bayesian methods, it is possible to generate new outliers when tight parameter smoothing relationships are implemented. In our case, we initially reported the existence of a single deviant observation, however the strict parameter specification employed in the BGWR model generated 10 new outliers.

As a robustness test, we replace the distance decay with a contiguity smoothing relationship, thus, neighboring observations are now assumed to be exclusively affected by adjacent counties. Notwithstanding that the contiguity smoothing relationship produces an estimate of $\delta=5$ when a diffuse prior of 20.42 is set, indicating some inconsistency between the smoothing specification and the data, the parameter estimates are very similar to the ones obtained under the distance decay relationship, they do not show systematic bias, are smoother and exhibit higher precision than GWR estimates. In particular, we find that 105 observations have negative coefficients for both explanatory variables, 71 of them have statistically significant estimates for geography and institutions with $95 \%$ probability, 10 have significant estimates with $95 \%$ probability for institutions and $90 \%$ for geography. Two observations have the opposite outcome. These results are shown in Figure 5. 
Figure 3: BGWR and GWR Parameter Estimates
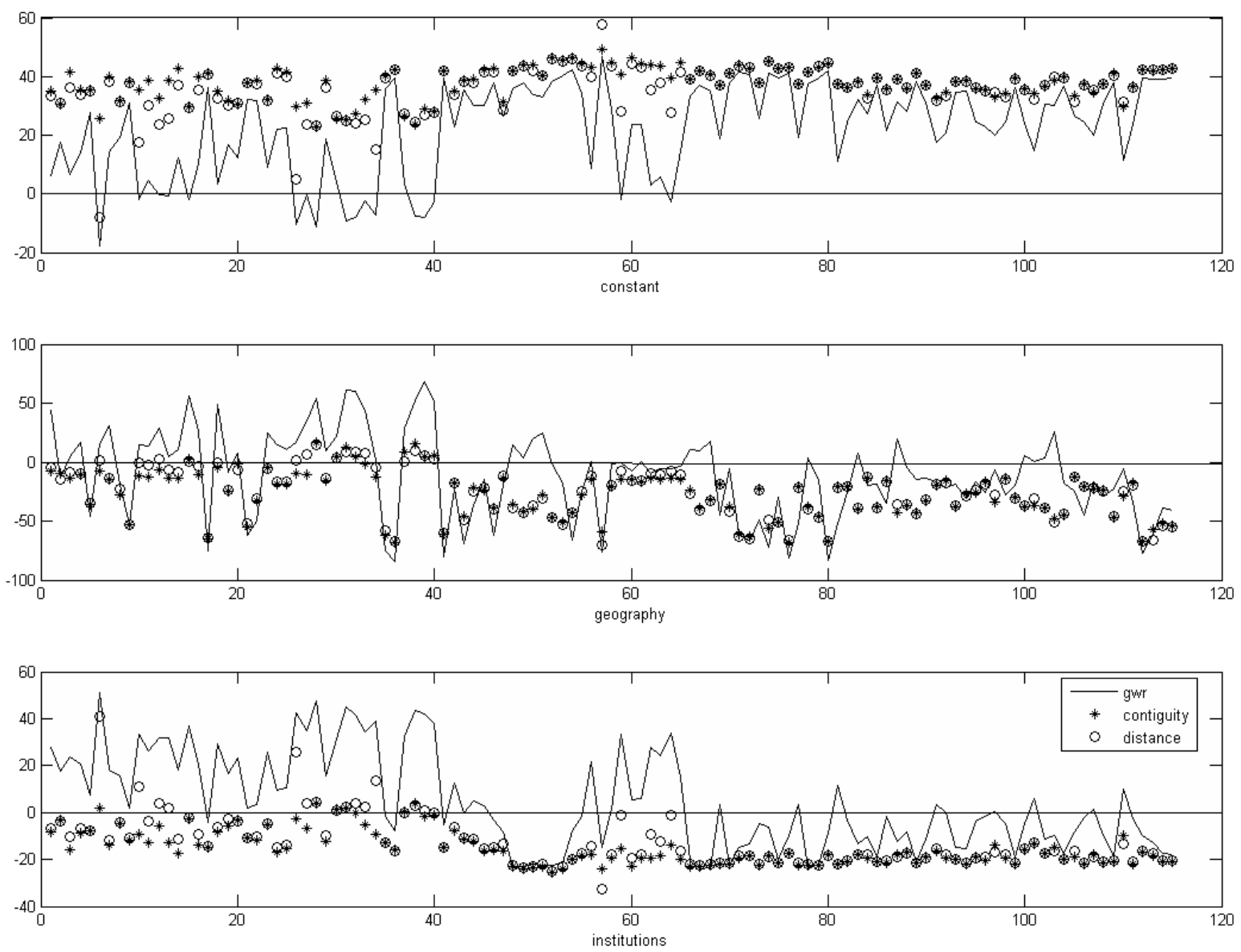

The horizontal scale is the observation number. The counties are ordered alphabetically by state and county. The vertical axis is the level of the coefficient. A negative sign on the coefficients means that an increase in mountainousness or local land control is associated with a decline in poverty. 
苟

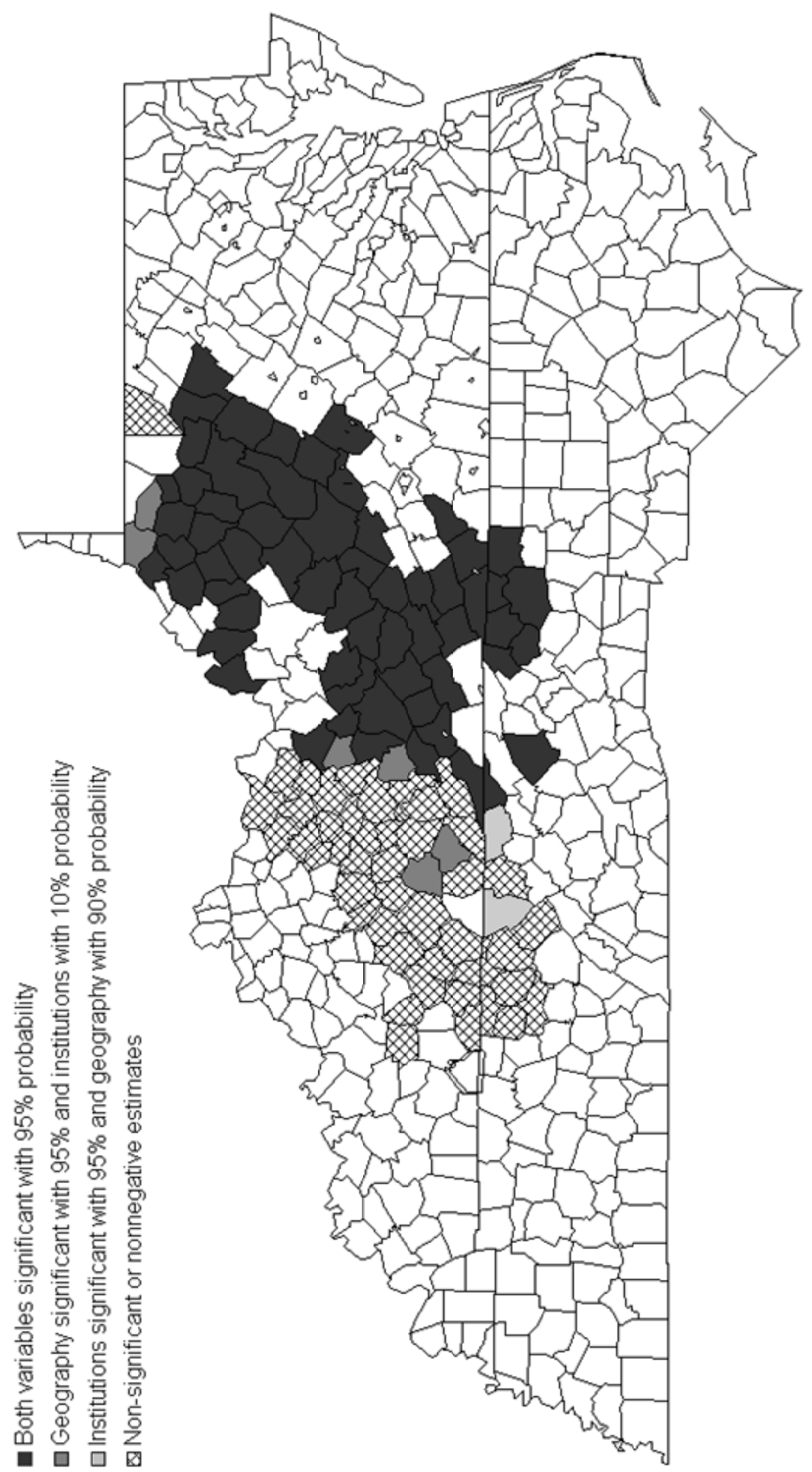




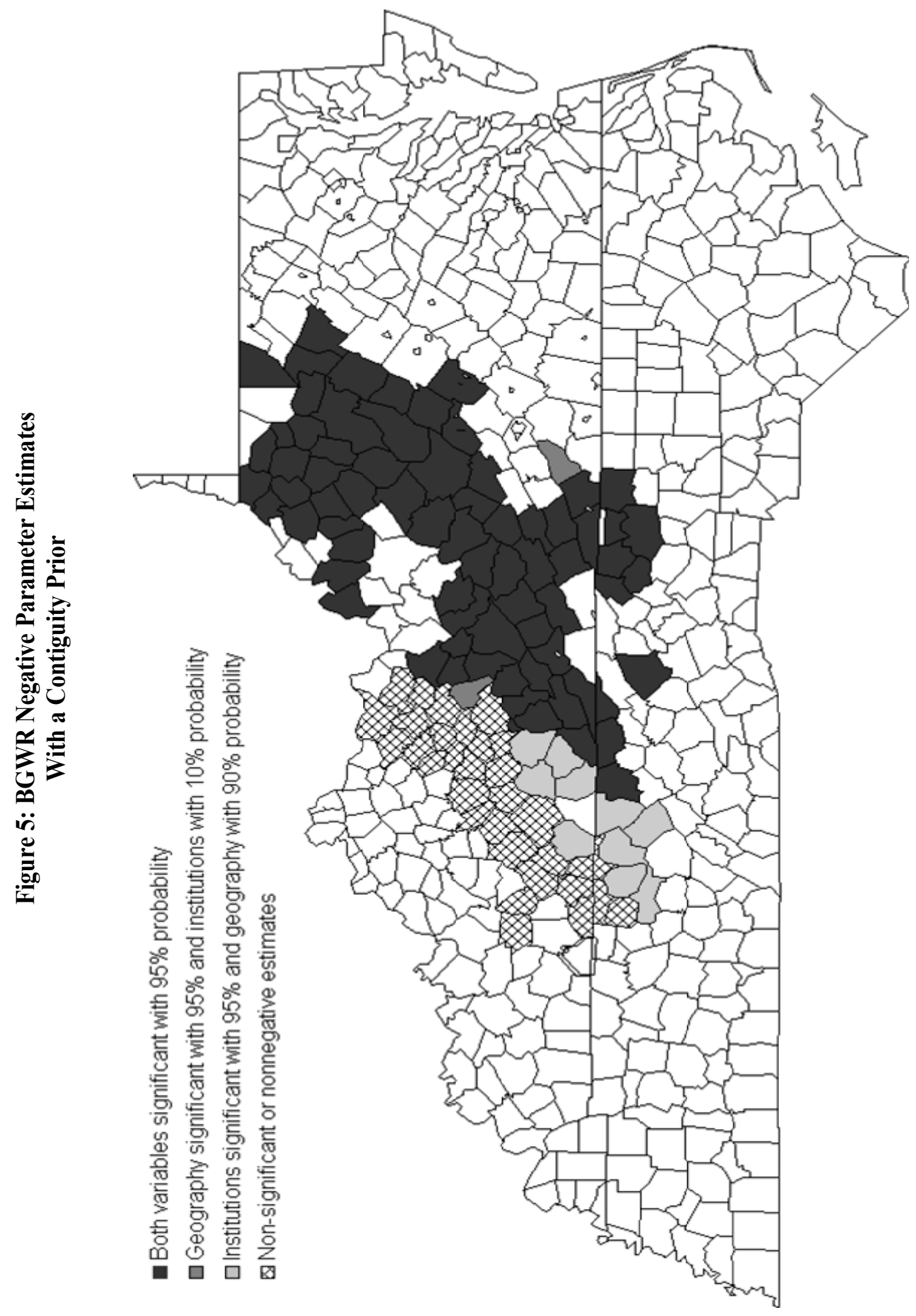


Looking at Figures 4 and 5 with the BWGR results indicated by county, the vast majority of counties have significant and negative coefficients. Thirty-eight out of the 48 counties where this is not true are located in the more western part of the sample, most of them located in eastern Kentucky and the Cumberland Plateau of middle Tennessee. In Figure 1, it is clear that this western region (region 3) was settled somewhat later than the rest of the sample and thus the strength of the impact of the original colonial land-owning structure may have been diminished. ${ }^{24}$

\section{Conclusions}

This paper supports the importance of institutions and geography in development. Theories about the impact of these factors are open-ended, and so both explanations could easily be true. The geography of the region is, of course, exogenous to the other variables studied. The institutional arrangements of early Appalachia are also exogenous to the other variables in that they were decided in part by political and financial concerns thousands of miles away. It must be stressed that measures of geography and institutions are not being used as instrumental variables in this study. Many other papers have used instrumental variables as proxies for nonspecific institutions. The advantage of this study is that it examines the exact geographical and institutional factors that have independently been linked to the development of the region. As noted, many have called for subnational studies on growth and development issues. While this study only looks at a small area of the world, our view is that, if similar studies of other regions were done, it could eventually allow some conclusions to be drawn about the roles of geography and institutions in the international context. Another interesting point of this study is the demonstration of the importance of initial conditions. Of course, poverty 200 years after settlement would naturally have been impacted by developments in the intervening years. This is one reason metropolitan areas, which have been more subject to change, were excluded from the study.

It would go too far to claim that the evidence shows mountainousness is not the cause of poverty in Appalachia, however, the evidence reviewed in fact supports the opposite conclusion. It is also interesting that the enormous expenditures on highways in Appalachia by the federal government have not ended poverty more than 40 years after the antipoverty program began. One explanation of the finding in this paper could be that the most mountainous areas of Appalachia are also the most scenic and that this has created job opportunities not available in less mountainous areas. Tourism had already become an important industry in Appalachia by the 1840s.

\footnotetext{
${ }^{24}$ Dunaway (1995) discusses four historical resettlement phases in Appalachia, the first one taking place before the 1763 Proclamation Line was mandated and covering western Maryland, the Valley of Virginia, northwestern North Carolina, and West Virginia's eastern and Ohio River edges. The second phase included upper-east Tennessee, northwestern North Carolina and the area around Madison County, Kentucky between 1770 and 1789. The third stage covered eastern Kentucky, the Cumberland Plateau of middle Tennessee, southwestern North Carolina and central West Virginia during the post-Revolutionary expansion. The final phase occurred during the late 1830 s after the forced removal of the remaining Native Americans.
} 
It must be stressed that this paper is not an attempt to develop an overall theory of economic growth in Appalachia. But rather it is an attempt to find why Appalachia did not advance to the production frontier, perhaps as represented by the eastern seaboard of the United States. More general growth models, such is in Galor (2005), might be used to describe this overall process. In our view, this work is consistent with the model of Parente and Prescott (2000) that tries to look for reasons why regions might be trapped inside the production frontier. The evidence examined indicates that land policies in the period immediately before settlement by Euro-Americans tended to create an elite that, through its rent-seeking behavior, retarded growth and contributed to poverty. 


\section{References}

Acemoglu, Daron, Simon Johnson, and J. Robinson, 2001, "The Colonial Origins of Comparative Development: An Empirical Investigation," American Economic Review, Vol. 91, pp. 1,369-1,401.

— 2004, "Institutions as the Fundamental Cause of Long-Run Growth," NBER Working Paper 10481 (Cambridge, Massachusetts: National Bureau of Economic Research).

Aghion, Philippe, and Steven N. Durlauf, 2005, Handbook of Economic Growth (Amsterdam: Elsevier).

Banerjee, Abhijit, and Lakshmi Iyer, 2005, "History, Institutions, and Economic Performance: The Legacy of Colonial Land Tenure Systems in India," American Economic Review, Vol. 95, No. 4, pp. 1,190-1,213

Besley, Timothy, and Robin Burgess, 2003, "Halving Global Poverty," Journal of Economic Perspectives, Vol. 17, No. 3, pp. 3-22.

Caselli, Francesco, 2005, "Accounting for Cross-Country Income Differences," in Handbook of Economic Growth, ed. by Philippe Aghion and Steven N. Durlauf (Amsterdam: Elsevier).

Diamond, Jared, 1997, Guns, Germs and Steel (New York: W. W. Norton).

Dunaway, Wilma A., 1995, "Speculators and Settler Capitalists: Unthinking the Mythology about Appalachian Landholding, 1790-1860," in Appalachia in the Making: The Mountain South in the Nineteenth Century, ed. by Mary Beth Pudup, Dwight Billings, and Altina Waller (Chapel Hill: University of North Carolina Press).

— 1996, The First American Frontier: Transition to Capitalism in Southern Appalachia, 1700-1860 (Chapel Hill: University of North Carolina Press).

- 1996, The Repeopling of Southern Appalachia, 1740-1840, [Map 3.1], in The First American Frontier: Transition to Capitalism in Southern Appalachia, 1700-1860 (Chapel Hill: University of North Carolina Press), p. 54.

Duncan, Cynthia M., 1992, "Persistent Poverty in Appalachia: Scarce Work and Rigid Stratification," in Rural Poverty in America, ed. by Cynthia M. Duncan (Westport, Connecticut: Auburn House).

Durlauf, Steven N., Paul A. Johnson, and Jonathan R.W. Temple, 2005, "Growth Econometrics," in Handbook of Economic Growth, ed. by Philippe Aghion and Steven N. Durlauf (Amsterdam: Elsevier). 
Easterly, William Russell, 2001, The Elusive Quest for Growth: Economists' Adventures and Misadventures in the Tropics (Cambridge, Massachusetts: MIT Press).

— and Ross Levine, 2003, "Tropics, Germs and Crops: How Endowments Influence Economic Development,” Journal of Monetary Economics, Vol. 50. pp. 3-39.

Engerman, Stanley L., and Kenneth L. Sokoloff, 2002, "Factor Endowments, Inequality, and Paths of Development among New World Economies," Economia, Vol. 3 (Fall) pp. 41-88.

Gallup, J.L., and J.D. Sachs with A. D. Mellinger, 1998, "Geography and Economic Development," in Annual World Bank Conference on Economic Development 1998, ed. by Boris Pleskovic and Joseph E. Stiglitz (Washington: World Bank).

Galor, Oded, 2005, "From Stagnation to Growth: Unified Growth Theory," in Handbook of Economic Growth, ed. by Philippe Aghion and Steven N. Durlauf (Amsterdam: Elsevier).

Glaeser, Edward L., Rafael La Porta, Florencio Lopez-De-Silanes, Andrei Shleifer, 2004, “Do Institutions Cause Growth?” Journal of Economic Growth, Vol. 9, pp. 271-303.

Kanbur, Ravi, 2001, "Economic Policy, Distribution and Poverty: The Nature of Disagreements," World Development, Vol. 29, pp. 1,083-94 (New York)

Khan, Mahmood Hasan, 2000, "Rural Poverty in Developing Countries: Issues and Policies," IMF Working Paper 00/78 (Washington: International Monetary Fund).

Lee, K.W., "Fair Elections in West Virginia," in Appalachia: Its People, Heritage and Problems, ed. by Frank S. Riddel, Kendall (Dubuque, Iowa: Hunt Publishing).

LeSage, James P., 1999, The Theory and Practice of Spatial Econometrics. A manual to accompany the spatial econometrics toolbox at www.spatial-econometrics.com.

— 2004, "A Family of Geographically Weighted Regression Models," in Econometrics for Spatial Models, Recent Advances, ed. by Luc Anselin, J.G.M. Florax and S. Rey, Spring-Verlag, pp. 241-264.

_ 1997, "Bayesian Estimation of Spatial Autoregressive Models," International Regional Science Review, Vol. 20, Nos. 1\&2, pp. 113-129.

Mitchener, Kris James, and Ian W. Mclean, 2003, "The Productivity of US States Since 1880," Journal of Economic Growth, Vol. 8, pp. 73-114 (Kluwer Academic Publishers).

North, Douglas C., 1981, Structure and Change in Economic History (New York: Norton and Co.). 
Olsson, Ola, and Douglas A. Hibbs, Jr., 2005, "Biogeography and Long-Run Economic Development," European Economic Review, Vol. 49, pp. 909-938 (Amsterdam: Elsevier).

Parente, Stephen L. and Edward C. Prescott, 2000, Barriers to Riches (Cambridge, Massachusetts: MIT Press).

—_ 2004, "A Unified Theory of the Evolution of International Income Levels," Federal Reserve Bank of Minneapolis, Research Department Staff Report No. 333.

Pollard, Kelvin M., 2003, “Appalachia at the Millennium: An Overview of Results from Census 2000," unpublished (Washington: Population Reference Bureau).

Rappaport, Jordan, and Jeffrey D. Sachs, 2003, "The United States as a Costal Nation," Journal of Economic Growth, Vol. 8, pp. 5-46 (Kluwer Academic Publishers).

Ravallion, Martin, 2001, "Growth, Inequality and Poverty: Looking Beyond Averages," World Development, Vol. 29, No. 11 (United Kingdom).

Riddel, Frank S., 1974, Appalachia: Its People, Heritage and Problems (Dubuque, Iowa: Kendall/Hunt Publishing Co.).

Rodrik, Dani, Arvind Subramanian, and Francesco Trebbi, 2002, "Institutions Rule: The Primacy of Institutions over Geography and Integration in Economic Development," NBER Working Paper 9305 (Cambridge, Massachusetts: National Bureau of Economic Research).

Santopietro, George D., 2002, "Analyzing Income Convergence and the Country Level: The Case of the Development in Central Appalachia," Journal of Economic Issues, Vol. 36, No. 4, December.

Srinivasan, T. N., 2001, "Growth and Poverty Alleviation: Lessons from Development Experience." Paper presented at the High-Level Symposium on Alternative Development Paradigms and Poverty Reduction (Asian Development Bank Institute).

U.S. Census Bureau, 2003, Percent of Total Population in Poverty: 2003. Small Area Income and Poverty Estimates (SAIPE) Program. http://www.census.gov/hhes/www/saipe/stcty/sc03layout.html.

Venebles, Anthony, 1998, "Comment on Gallup et al," Annual World Bank Conference on Economic Development 1998, ed. by Boris Pleskovic and Joseph E. Stiglitz (Washington: World Bank).

Widner, Ralph R., "The Four Appalachias," in Appalachia: Its People, Heritage and Problems, ed. by Frank S. Riddel (Dubuque, Iowa: Kendall/Hunt Publishing Co.) 
Wood, Lawrence E., and Gregory A. Bischak, 2000, "Progress and Challenges in Reducing Economic Distress in Appalachia: An Analysis of National and Regional Trends Since 1960," unpublished (Washington: Appalachian Regional Commission). 